\title{
BMJ Open Joint associations of smoking and physical activity with disability retirement: a register-linked cohort study
}

\author{
Tea Lallukka, ${ }^{1,2}$ Ossi Rahkonen, ${ }^{1}$ Eero Lahelma, ${ }^{1}$ Jouni Lahti ${ }^{1}$
}

To cite: Lallukka T, Rahkonen 0, Lahelma E, et al. Joint associations of smoking and physical activity with disability retirement: a register-linked cohort study. BMJ Open 2015;5:e006988. doi:10.1136/bmjopen-2014006988

- Prepublication history for this paper is available online. To view these files please visit the journal online (http://dx.doi.org/10.1136/ bmjopen-2014-006988).

Received 22 October 2014 Revised 4 May 2015 Accepted 7 May 2015

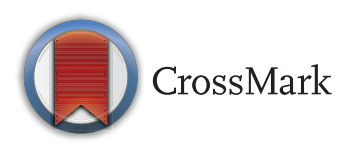

${ }^{1}$ Department of Public Health, University of Helsinki, Helsinki, Finland

${ }^{2}$ Centre of Expertise for Health and Work Ability \& Disability Prevention Research Centre, Finnish Institute of Occupational Health, Helsinki, Finland

Correspondence to Dr Tea Lallukka; tea.lallukka@ttl.fi

\section{ABSTRACT}

Objectives: We examined the risk of disability retirement by smoking and physical activity, and particularly whether the risk due to smoking is affected by the level of physical activity. Additionally, the contribution of baseline health, sociodemographic and work-related factors to the joint associations of smoking and physical activity with disability retirement was considered.

Design: Cohort study.

Setting: Helsinki, Finland.

Participants: Employees of the City of Helsinki, aged 40-60 years at baseline in 2000-2002, were followed up using complete register data from the Finnish Centre of Pensions until the end of $2010(n=6390$, with a consent to register linkage from $74 \%$ ).

Primary outcome measure: All-cause disability retirement (ICD-10).

Results: Altogether, 608 employees (9.5\%) retired due to disability during the follow-up. Cox regression models were fitted to examine the joint associations of smoking and physical activity with subsequent disability retirement. Never-smokers, ex-smokers and moderate smokers who were inactive or moderately active had an increased risk of disability retirement, but if they were vigorously active, they had no excess risk. Instead, all heavy smokers (15 or more cigarettes per day among women, and 20 or more among men), irrespective of physical activity, had an increased risk of disability retirement. The examined associations attenuated but remained for ex-smokers and heavy smokers after adjustments for gender, age,

socioeconomic position, mental and physical workload, problem drinking, body mass index and self-rated health. No gender interactions were found.

Conclusions: Vigorous physical activity might help prevent disability retirement not only among neversmokers, but even among ex-smokers and moderate smokers. However, among heavy smokers, physical activity is not sufficient to eliminate the adverse effects of smoking on health and work ability.

\section{INTRODUCTION}

Smoking and physical inactivity are prevalent public health problems and key risk factors
Strengths and limitations of this study

- A limitation of this study is that smoking, physical activity and covariates were self-reported at baseline only. However, as a strength, we were able to distinguish between the different volume and intensity of leisure-time physical activity and amount of smoking as well as smoking history.

- A further strength of this study was that the data about disability retirement were complete, and comprised all ICD-based disability retirement events derived from national registers.

- In all, the results highlight the importance of heavy smoking and physical inactivity as risk factors for subsequent register-based disability retirement, and that the risk among ex-smokers, moderate smokers and never-smokers can be shaped by the intensity of leisure-time physical activity.

for major chronic diseases, ${ }^{1-4}$ but their associations with disability retirement are inadequately understood. Early exit from working life due to disability retirement is a public health challenge and an economic burden for society. Thus, novel evidence about its preventable risk factors is needed for preventing the decline in work ability and tackling the individual, organisational and societal burdens related to disability retirement. Around $7 \%$ of all working-aged people are currently on disability pension in Finland, and the prevalence sharply increases after midlife. ${ }^{5}$ This highlights the need to shed light on the factors associated with early exit from the labour market due to disability among ageing employees in particular.

Some earlier studies have found associations between smoking and disability retirement, or work disability comprising both sickness absence and disability retirement. ${ }^{6-12}$ Physical inactivity has also been associated with work disability. ${ }^{13-15}$ The association between smoking and disability retirement 
appears to be dose-dependent, that is, the risk of disability retirement tends to increase with heavier smoking. ${ }^{6-8} 12$ However, some studies have only examined current smoking, ${ }^{9} 16$ and in a large study comprising 11 European countries, current smoking was unassociated with exit from the labour market due to disability. ${ }^{17}$ Studies focused on smoking have sometimes considered physical activity. For example, an earlier study found that heavy smoking is associated with the risk of disability retirement among women even after adjusting for physical activity, while the association attenuated among men after adjusting for socioeconomic position and further by physical activity. ${ }^{12}$ Both smoking and physical inactivity independently increase the risk of disability retirement, while physical activity could decrease the risk of disability retirement. Although some studies have had only self-reported data on work disability, ${ }^{14}{ }^{15}$ a recent meta-analysis further supported the importance of physical inactivity to the risk of disability retirement. ${ }^{18}$ The meta-analyses included 10 different studies and reported 17 associations, of which 8 were statistically significant. A pooled estimate could not be computed due to many differences in definitions and cut-off points used for physical inactivity.

The previous studies are, however, heterogeneous, as measures and operationalisation of smoking and physical activity, outcomes as well as study populations have varied. Thus, the evidence yielded is neither comprehensive nor consistent. Furthermore, joint associations of smoking and physical activity with subsequent work disability have been studied very little. Smokers typically exercise less as compared to non-smokers, and physically active smokers might have a reduced risk of, for example, pulmonary disease, as physical activity could help reduce the decline in lung function among smokers. ${ }^{1920}$ A potential explanation for the beneficial effects of physical activity is related to its antiinflammatory potential. ${ }^{21}$ This could be beneficial to both smokers and non-smokers.

The joint associations of smoking and physical activity with lung functions support examining their joint contribution to other health outcomes including disability retirement. A recent study reported a statistically significant $p$ value for an interaction between smoking and physical activity when predicting the risk of disability retirement due to musculoskeletal disorders and circulatory diseases. ${ }^{22}$ All-cause disability retirement was not included, and the joint associations were not reported. An earlier study focusing on the joint associations found a higher risk of self-reported work disability only among those smokers who were inactive, whereas smokers who were physically active at least once a week were not at risk of work disability. ${ }^{23}$ However, this small-scale study did not distinguish between different levels of physical activity or consider the amount of smoking and ex-smoking. Thus, it is not known whether the amount and intensity of physical activity affects the risk and whether physical activity is protective of disability retirement among heavy and moderate smokers. One might assume that the risk of disability retirement varies by the amount of smoking, and that physical activity shapes the risk. Furthermore, since ex-smokers were combined with the never-smokers in the earlier study ${ }^{23}$ it is not known whether ex-smokers continue to be at higher risk of disability retirement and whether the level of physical activity shapes that risk. Consequently, the joint associations of smoking and physical activity with disability retirement need to be examined in different populations with recent data to confirm whether the associations can be found across employed populations and over time. In sum, the focus on the joint association is an extension to the previous studies that have examined the independent associations of smoking or physical activity with disability retirement. Such analyses cannot address the above questions or confirm whether the risk of disability retirement among never-smokers, former smokers, occasional smokers or heavy smokers is equally affected by their amount and intensity of physical activity. This can be addressed by distinguishing these groups in a joint variable.

Finally, although the health of the working-age population has generally improved, the disability retirement rates remain continuously high across OECD countries. ${ }^{24}$ Given that notable demographic changes with the ageing populations are taking place during the next decades further highlights the need for examining the determinants of work disability. Thus, in efforts to extend working life, this information can be used in finding potential risk groups for effective and early prevention. Prevalence of smoking in Finland has been declining during the previous decade, and is somewhat lower as compared to the other OECD countries. ${ }^{25}{ }^{26}$ However, roughly a fifth of working-aged men and a sixth of working-aged women are still current smokers. ${ }^{27}$ Likewise, current trends suggest that the proportion of those who are physically inactive has declined steadily. ${ }^{28}$ Despite the positive trends, physical inactivity and smoking remain prevalent risk factors challenging public health and work ability. Additionally, owing to declining response rates to surveys, it is difficult to estimate the actual trends. We hypothesised that non-smoking and physical activity protects against disability retirement among midlife employees, and more specifically that the risk of disability retirement among smokers and nonsmokers is affected by the volume and intensity of their physical activity.

The main aim of this study was to examine the joint associations between smoking, physical activity and disability retirement. We first examined the separate effects of smoking and physical activity on subsequent risk of disability retirement, and then formed a joint variable to further examine whether the risk of disability retirement due to smoking varies by the level of physical activity. An additional aim was to consider the effects of a range of covariates on the associations. 


\section{METHODS}

\section{Study population}

The Helsinki Health Study data were used for the purposes of this study. The study was set to examine sociodemographic and work-related determinants of health and well-being of employees of the City of Helsinki, Finland. ${ }^{29}$ The Helsinki Health Study baseline questionnaire survey data were collected in 2000-2002 among all women and men who turned 40,45, 50, 55 or 60 at each survey year $(n=13344)$. The mean age of participants was 49.4 years. Altogether, 8960 (80\% women) responded to the survey (response rate $67 \%$ ). The proportion of women in the data corresponds to that in the female-dominated target population in this age group $(78 \%)$, and the public sector more generally. Further details of the cohort and data collection can be found elsewhere. ${ }^{29}$ These data were prospectively linked with complete register data on all-cause disability retirement (ICD-10) from the Finnish Centre for Pensions, using personal identification numbers assigned to each citizen in Finland. The linkage was done for those respondents who had provided informed consent for such linkage $(\mathrm{n}=6606,74 \%)$. After excluding those with missing data on the studied variables (smoking, $\mathrm{n}=64$, physical activity, $\mathrm{n}=43$, all covariates altogether, $\mathrm{n}=109$ ), altogether 5016 women and 1374 men were eligible for the analyses $(n=6390)$. The follow-up began after returning the baseline questionnaire and continued until the end of 2010, with a mean follow-up of around 8 years.

\section{Smoking and leisure-time physical activity}

Smoking and leisure-time physical activity were selfreported at baseline.

The respondents were first asked whether they currently smoked cigarettes, cigars or pipes (yes, no). As practically all smoking (99\% among men and 99.9\% among women) was cigarette smoking, ${ }^{30}$ all the types were analysed together. Additionally, the respondents were asked whether they had previously smoked. The smokers further reported their smoking intensity, that is, the number of cigarettes they smoked daily. On the basis of responses to questions on smoking history and intensity, and following previous procedures, ${ }^{31}$ the respondents were classified into four groups: non-smokers (ie, never smokers), ex-smokers, moderate smokers and heavy smokers. Among women, moderate smoking referred to 1-14 cigarettes per day, and among men 1-19 cigarettes per day. Heavy smoking referred to smoking 15 or more cigarettes among women and 20 or more cigarettes per day among men. A lower cut-off point for heavy smoking among women was due to gender difference in the distribution of the amount of heavy smoking. The same cut-off point for men has also been used previously in other earlier studies by us and others, and it has been particularly strongly associated with the risk of disability. ${ }^{6} 1031$

Leisure-time physical activity (including commuting) was measured with questions about average weekly hours of physical activity in four intensity grades. The reference time was previously 12 months. Four intensity grades distinguished walking, brisk walking, jogging and running or any equivalent physical activity. Five response alternatives were given, with a range from zero hours to more than $4 \mathrm{~h}$ a week for each intensity grade of activity. On the basis of the responses (intensity of activity and the hours spent on each intensity grade), metabolic equivalent values (METs) were approximated by using previously developed procedures. ${ }^{13}{ }^{32-34}$ In brief, METs are calculated by multiplying the weekly hours by the estimated MET of each requested intensity grade of physical activity. A MET value of one corresponds to resting metabolic activity. The respondents were classified into three groups based on a classification that broadly followed the current national recommendations for physical activity: inactive, moderately active and vigorously active. ${ }^{35}$ Thus, inactivity referred to 14 or less MET-hours per week. Moderately active referred to more than 14 MET-hours (eg, brisk walking for $2.5 \mathrm{~h}$ equals 15 MET-hours). Among those vigorously active, the MET values also comprised vigorous activity such as jogging, running or the like (eg, jogging or equivalent activity for 45 min per week and brisk walking or equivalent activity for $1.5 \mathrm{~h}$ per week).

The joint variable was then formed using vigorously active non-smokers as a reference category. This was done as both non-smokers and vigorously active smokers have the lowest risk of disability retirement as also shown in figures 1-2. Additionally, never-smokers were not distinguished from ex-smokers in the only earlier study focused on smoking, physical activity and self-reported work disability. ${ }^{23}$ To examine the effects of smoking at different levels of physical activity, the following groups

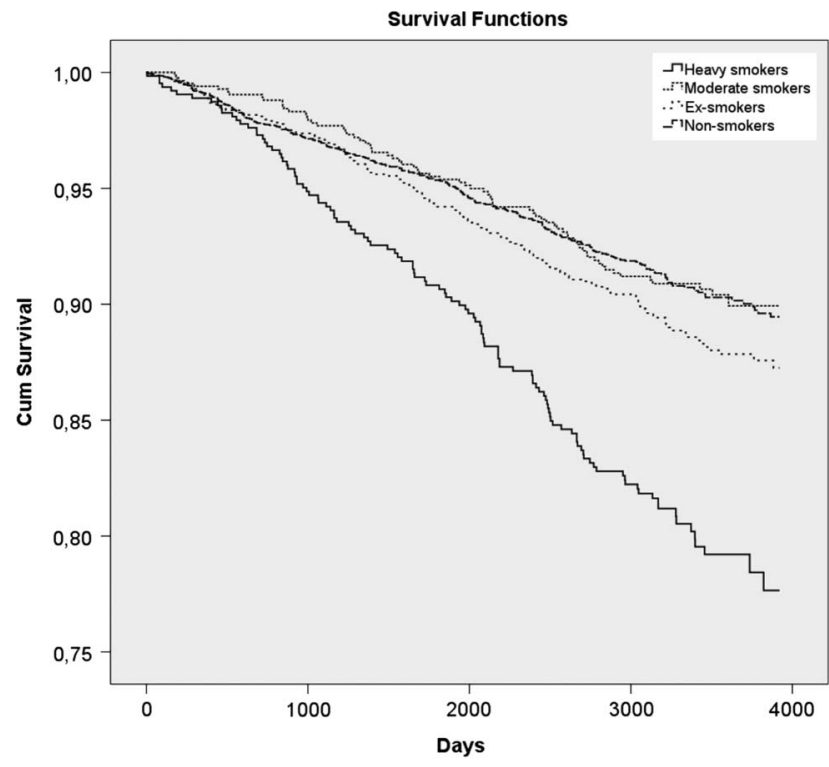

Figure 1 Proportions (\%) of women and men not on disability retirement over follow-up ( $n=6390$, events $n=608)$. Kaplan-Meier survival functions by smoking status. 


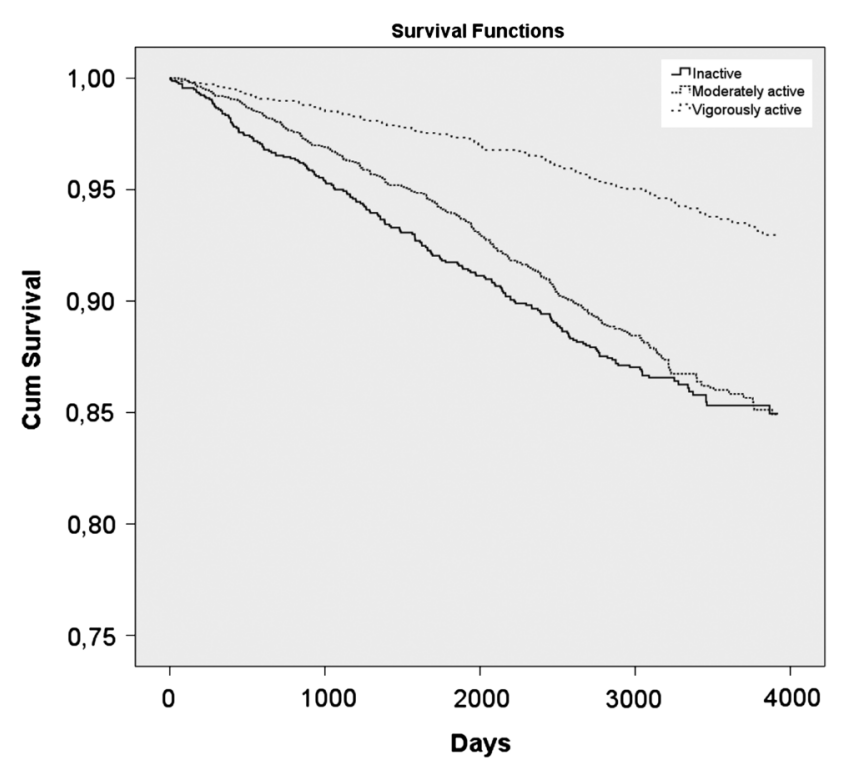

Figure 2 Proportions (\%) of women and men not on disability retirement over follow-up ( $n=6390$, events $n=608)$. Kaplan-Meier survival functions by the level of leisure-time physical activity.

were formed and compared to the reference category: inactive non-smokers, moderately active non-smokers, inactive ex-smokers, moderately active ex-smokers, vigorously active ex-smokers, inactive moderate smokers, moderately active moderate smokers, vigorously active moderate smokers, inactive heavy smokers, moderately active heavy smokers and vigorously active heavy smokers.

\section{Disability retirement}

Permanent disability pension can be granted in Finland based on incapacity to work due to a disease diagnosed by a physician. ${ }^{36}$ Illness, injury or impairment has to have decreased the capacity to work by at least $60 \%$ during a year preceding the assessment. Therefore, disability retirement is typically preceded by sickness absence of 300 days or more. The decision is focused on the ability to work. A diagnosed disease is a necessary but not a sufficient condition for granting disability retirement. In addition, other factors such as age, education, living and working conditions and work history are taken into account when the employee's opportunities to continue working are assessed. ${ }^{5}$ Since work disability is usually partial, ${ }^{37}$ the remaining work capacity could be used if, for example, working conditions were modified. Thus, this study considers the importance of sociodemographic and work-related factors to the examined associations. Disability retirement events were classified based on ICD-10 diagnoses. We focused on all-cause disability retirement.

\section{Covariates}

In line with the above described disability retirement granting process, we considered gender, age, socioeconomic, work-related and health-related factors as covariates. Since disability retirement is socioeconomically patterned, ${ }^{38} 39$ socioeconomic position was measured using occupational social class from the employer's personnel register. Four groups were used: managers and professionals, semiprofessionals, clerical employees and manual workers. Managers and professionals served as a reference group. Mental and physical workload was examined using two single items asking whether the respondents perceived their work as very light, light, strenuous or very strenuous mentally or physically, and dichotomised as heavy or light. Light work was used as a reference for both mentally and physically strenuous work, following previous procedures. ${ }^{40}$ Problem drinking was based on the four-item CAGE (Cut-down, Annoyed, Guilty, Eye-opener) questionnaire. ${ }^{41}$ Those with no indication for problem drinking served as a reference group. For women, the cut-off point indicating problem drinking was two positive responses, and for men, three positive responses. This measure was adjusted for as it has been associated with disability retirement. ${ }^{42}$ Body mass index (a continuous variable) was computed from selfreported weight and height $\left(\mathrm{kg} / \mathrm{m}^{2}\right)$. It was adjusted for, as obesity was associated with physical activity and smoking $(p<0.0001)$, and it has been strongly and independently associated with disability retirement. ${ }^{43}$ Self-rated health was a single item derived from the short form 36 health questionnaire (SF-36). ${ }^{44} 45$ Those with good health served as a reference group. The item has also been widely used earlier and it is a strong and independent predictor of disability retirement. ${ }^{46}$

\section{Ethical considerations}

The Helsinki Health Study protocol has been approved by the ethics committees of the Department of Public Health, University of Helsinki, Finland and the City of Helsinki Health Authorities.

\section{Statistical analyses}

Descriptive analyses were computed first, showing the distribution of all variables, and cross-tabulating the exposure and covariates with disability retirement events. Statistical significance is shown with $\mathrm{p}$ values $\left(\chi^{2}\right)$. The Kaplan-Meier survival curves next show the proportion of those not on disability retirements over the follow-up by smoking and physical activity. Finally, the Cox regression models were fitted to examine the joint associations of physical activity and smoking with subsequent allcause disability retirement. Proportionality assumptions were tested and met. No gender interactions were found ( $p$ value for interaction $=0.5$ ), and thus the analyses were carried out in pooled data adjusting for gender. In the analyses, those who turned 63 years $(\mathrm{n}=1092)$, retired based on their normal retirement age $(n=830)$ or died $(n=43)$ were censored. Age-based censoring was done because, after the age of 63 , disability retirement is no longer granted in Finland. Model 1 was adjusted for age and gender. Further models comprised the covariates in Model 1. Model 2 was additionally adjusted for 
socioeconomic position and physical and mental strenuousness of work, and Model 3 was the full model, adjusting for variables in Model 2, as well as for problem drinking, body mass index and self-rated health.

In addition, sensitivity analyses were conducted to confirm the associations. First, we examined causespecific disability retirement using the two leading causes as the outcomes. Second, the effects of each of the covariates as well as marital status were tested in separate models to examine which of the factors made the strongest contribution to the examined association, and to confirm that the factors can be combined and fit cumulative yet parsimonious models.

\section{RESULTS}

Over the follow-up, there were altogether $608(9.5 \%)$ disability retirement events (table 1 ). Both smoking and physical activity strongly contributed to the risk of disability retirement. Among vigorously active non-smokers, only less than 1 of 20 ended up in disability retirement, as compared to a fifth of heavy smokers who were inactive or only moderately active at leisure time.

Survival curves of non-smokers and moderate smokers were broadly similar, but ex-smokers and particularly heavy smokers were more likely to retire due to disability over follow-up (figure 2). Similarly, survival curves of physically inactive and moderately active smokers were similar, while the vigorously active smokers were least likely to retire due to disability over the follow-up.

After adjusting for gender and age (Model 1), results from the Cox regression models showed that nonsmokers who were moderately active $(\mathrm{HR}=1.87,95 \%$ CI 1.37 to 2.55$)$ or inactive ( $\mathrm{HR}=2.08,95 \%$ CI 1.48 to 2.93$)$ had a higher risk of disability retirement (table 2). Among ex-smokers, the risk of disability retirement was also increased among those moderately active $(\mathrm{HR}=2.39$, $95 \% 1.69$ to 3.36$)$ and inactive (HR=2.57, $95 \% 1.75$ to 3.77). Instead, vigorously active ex-smokers had no excess risk. Similar associations were further found for moderate smokers, who were moderately active ( $\mathrm{HR}=2.09,95 \% 1.38$ to 3.17 ), or inactive ( $\mathrm{HR}=2.03,95 \%$ 1.21 to 3.41). As with the ex-smokers, the risk of disability retirement was not increased among those moderate smokers with vigorous physical activity ( $\mathrm{HR}=1.34,95 \%$ 0.77 to 2.34 ). Among heavy smokers, also the vigorously active had a higher risk of disability retirement ( $\mathrm{HR}=2.79,95 \%$ CI 1.62 to 4.79$)$, while the highest risks were found among heavy smokers who were moderately active $(\mathrm{HR}=4.18,95 \%$ CI 2.86 to 6.10$)$ or inactive $(\mathrm{HR}=4.16,95 \%$ CI 2.80 to 6.16$)$.

In Model 2, further adjustments for sociodemographic and work-related factors somewhat attenuated the associations. However, they remained except for moderate smokers who were inactive, the association attenuated and was of borderline significance only (HR=1.67 95\% CI 0.99 to 2.81). The attenuation was clearest among heavy smokers. Thus, after adjusting for gender, age,
Table 1 Distributions of study variables, and disability retirement events by the study variables during the follow-up ( $p$ values from cross-tabulations between each variable of interest and disability retirement events)

\begin{tabular}{|c|c|c|c|}
\hline & $\begin{array}{l}\text { Distribution } \\
\text { (n) }\end{array}$ & $\begin{array}{l}\text { Disability } \\
\text { retirement } \\
\text { events (\%) }\end{array}$ & p Value \\
\hline \multicolumn{4}{|l|}{ Gender } \\
\hline Women & 5016 & $494(9.8)$ & \\
\hline Men & 1374 & 114 (8.3) & 0.082 \\
\hline \multicolumn{4}{|l|}{ Age } \\
\hline 40 & 1281 & $39(3.0)$ & \\
\hline 45 & 1380 & $78(5.7)$ & \\
\hline 50 & 1366 & $192(14.1)$ & \\
\hline 55 & 1603 & $225(14.0)$ & \\
\hline 60 & 760 & $74(9.7)$ & $<0.0001$ \\
\hline \multicolumn{4}{|c|}{ Socioeconomic position } \\
\hline Manual workers & 859 & $152(17.0)$ & \\
\hline $\begin{array}{l}\text { Routine } \\
\text { non-manuals }\end{array}$ & 2191 & $254(11.6)$ & \\
\hline Semiprofessionals & 1246 & $106(8.5)$ & \\
\hline $\begin{array}{l}\text { Managers/ } \\
\text { professionals }\end{array}$ & 2058 & $96(4.7)$ & $<0.0001$ \\
\hline \multicolumn{4}{|c|}{ Physically strenuous work } \\
\hline No & 4305 & $302(7.0)$ & \\
\hline Yes & 2085 & $306(14.7)$ & $<0.0001$ \\
\hline \multicolumn{4}{|c|}{ Mentally strenuous work } \\
\hline No & 5490 & $502(9.1)$ & \\
\hline Yes & 900 & $106(11.8)$ & 0.013 \\
\hline \multicolumn{4}{|l|}{ Drinking problem } \\
\hline No & 5264 & $480(9.1)$ & \\
\hline Yes & 1126 & $128(11.4)$ & 0.02 \\
\hline \multicolumn{4}{|l|}{ Body mass index } \\
\hline Normal & 3267 & $233(7.1)$ & \\
\hline Overweight & 2186 & $218(10.0)$ & \\
\hline Obese & 937 & $157(16.8)$ & $<0.0001$ \\
\hline \multicolumn{4}{|l|}{ Self-rated health } \\
\hline Poor & 1582 & $363(22.9)$ & \\
\hline Good & 4808 & $245(5.1)$ & $<0.0001$ \\
\hline \multicolumn{4}{|c|}{ Smoking and physical activity } \\
\hline Non-smokers & 3399 & $271(8.0)$ & \\
\hline Active vigorous & 1250 & $57(4.6)$ & \\
\hline Active moderate & 1395 & $134(9.6)$ & \\
\hline Inactive & 754 & $80(10.6)$ & \\
\hline Ex-smokers & 1533 & $154(10.0)$ & \\
\hline Active vigorous & 522 & $28(5.4)$ & \\
\hline Active moderate & 634 & $77(12.1)$ & \\
\hline Inactive & 377 & $49(13.0)$ & \\
\hline Moderate smokers & 836 & $71(8.5)$ & \\
\hline Active vigorous & 270 & $16(5.9)$ & \\
\hline Active moderate & 366 & $36(9.8)$ & \\
\hline Inactive & 200 & $19(9.5)$ & \\
\hline Heavy smokers & 622 & $112(18.0)$ & \\
\hline Active vigorous & 128 & 17 (13.3) & \\
\hline Active moderate & 262 & $51(19.5)$ & \\
\hline Inactive & 232 & $44(19.0)$ & $<0.0001$ \\
\hline All & 6390 & $608(9.5)$ & \\
\hline
\end{tabular}

socioeconomic position and physical and mental strenuousness at work, heavy smokers who were vigorously active continued to have a higher risk of disability retirement 


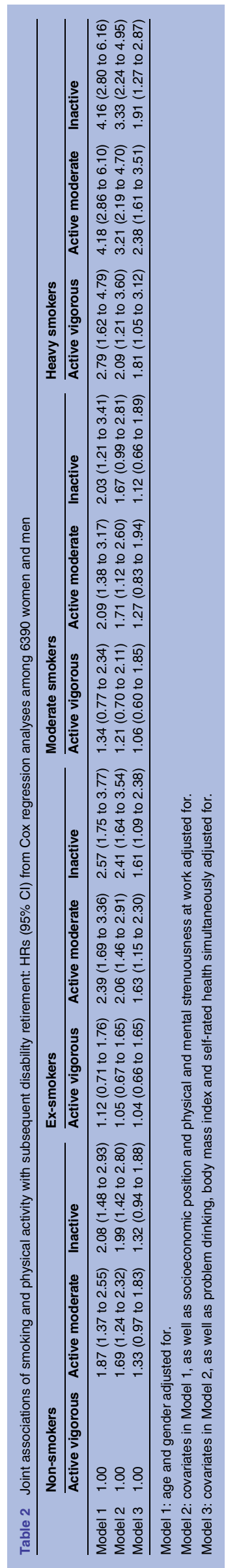

$(\mathrm{HR}=2.09$ 95\% CI 1.21 to 3.60$)$. The highest risks remained for those heavy smokers who were moderately active (HR=3.21 95\% CI 2.19 to 4.70$)$ or inactive (HR=3.33 $95 \%$ CI 2.24 to 4.95 ).

Full adjustment for all covariates resulted in the strongest attenuation of the associations (Model 3). For nonsmokers and moderate smokers who were moderately active, the associations reduced after full adjustment, while ex-smokers who were moderately active and inactive continued to have a higher risk of disability retirement. Among heavy smokers, the risk remained for all levels of physical activity. Thus, being vigorously active $(\mathrm{HR}=1.8195 \%$ CI 1.05 to 3.12), moderately active $(\mathrm{HR}=2.3895 \%$ CI 1.61 to 3.51$)$ or inactive $(\mathrm{HR}=1.91$; $95 \%$ CI 1.27 to 2.87 ) remained associated with disability retirement even after full adjustment.

\section{Sensitivity analyses}

In sensitivity analyses, similar patterns in the joint associations were found for both leading causes of disability retirement, musculoskeletal diseases (M00-M99) and mental disorders (F00-F99). A small number of events did not allow a more detailed cause-specific analysis to be displayed. Marital status was adjusted for as an additional covariate, but as it made a negligible contribution to the examined association and was unassociated with the outcome, it was excluded from the final models. As the individual contribution of each of the examined covariates was overall minor, we preferred to show the results from the cumulative models. The largest individual contribution was found for self-rated health (data not shown).

\section{DISCUSSION \\ Principal findings}

This study sought to examine the joint associations of smoking and physical activity with subsequent risk of disability retirement among midlife women and men. The main finding was that both smoking and physical activity contributed to the risk of disability retirement. Furthermore, the level of physical activity affected the risk of disability retirement among non-smokers, ex-smokers and moderate smokers. Thus, among vigorously active employees, only heavy smoking was associated with the risk of disability retirement, while ex-smokers and moderate smokers with vigorous physical activity had no excess risk. Considering that socioeconomic position and physical and mental strenuousness at work had mainly minor effects on the associations among non-smokers, ex-smokers and moderate smokers, the examined covariates accounted for a relatively large part of the associations among heavy smokers. After further including health-related factors, all of the associations attenuated, and the differences by the level of physical activity reduced particularly among heavy smokers. 


\section{Interpretation}

Few studies have previously examined smoking and physical activity as joint risk factors for health and work disability. Overall, our findings suggest that sufficient physical activity may help prevent disability retirement not only among non-smokers, but also among smokers. This is in line with a recent Brazilian study showing that among smokers, a higher level of physical activity is protective of chronic obstructive pulmonary disease, as compared to their matched non-smokers. ${ }^{19}$ Similarly, a Danish cohort study showed that among smokers, high levels of physical activity reduce the risk of lung function decline and pulmonary disease. ${ }^{20}$ Alternatively, smokers' low physical activity could be a marker of poor health functioning, or an undiagnosed disease. However, the association between smoking and work disability is dosedependent, as the risk reduced among moderate smokers but remained relatively high among all heavy smokers despite their level of physical activity. As the joint associations attenuated mostly for the heavy smokers after full adjustments, this suggests that the included sociodemographic, work-related and health factors largely contribute to the examined joint association. This is in line with a recent study reporting that the association between heavy smoking and the risk of disability retirement attenuated but remained among women, while the associations for ex-smokers, lighter smokers and all male smokers were reduced after adjustments for education, physical activity and other confounders. ${ }^{12}$

Only one previous study published nearly a couple of decades ago $^{23}$ has examined the joint associations between smoking, physical activity and work disability. Although there are notable differences in our study, our findings are in line with the earlier study showing that only physically inactive smokers have a higher work disability risk. In the previous study, work disability referred to self-reported sickness absence of 8 weeks or more during the previous year, or disability pension. Our study extends the earlier knowledge by showing in more detail the significance of the amount of smoking, smoking history and the intensity of physical activity to subsequent disability retirement. While the dichotomised measures used earlier are unable to distinguish between these risk groups, our study shows that the risk remains among ex-smokers who are moderately active or inactive, and that among heavy smokers even vigorous physical activity is not sufficient to counteract the risks associated with smoking, or prevent disability retirement. Furthermore, it needs to be highlighted that nonsmokers who are inactive or only moderately active might have an increased work disability risk, although the risks reduced after considering sociodemographic factors, working conditions and health. In addition to contributing to the indisputable adverse effects of smoking, this study further sheds light on the possibilities of physical activity to help modify the risk of disability retirement among smokers and non-smokers. Thus, a sufficient amount of vigorous physical activities should be promoted equally to non-smokers and smokers. A sufficient volume and intensity of physical activity most likely promotes well-being, health and functioning among employees overall, while also preventing decline in work ability.

Although the risk of work disability among ex-smokers continued to be high, this evidently does not suggest that smoking cessation has harmful consequences or is not recommended. Moreover, even though we accounted for baseline health and other key covariates, those who had stopped smoking could have done that due to an illness or after a physical examination, and their work ability could have been notably decreased even prior to the decision to quit smoking. Thus, it may not be surprising that ex-smoking has long-lasting harmful effects. It is also likely that most had smoked even for decades, as smoking is typically started in adolescence. ${ }^{47}$ Smoking is also a relatively stable behaviour. Accordingly, smoking cessation over the follow-up was rare in these data as well (data not shown).

The need to tackle the modifiable and preventable risk factors of work disability among employees is a shared challenge across the developed countries, as health and social policies are aiming to increase labour market participation in ageing populations. Since work disability is a major route to early exit from the workforce, evidence about the causes of work disability is important to social and health policies in efforts to extend work careers. In addition to health, work-related factors and other resources affect the ability to continue working, and therefore the prevention of work disability should consider all of these aspects and their links with the risk factors, such as the examined smoking and physical inactivity.

\section{Strengths and limitations}

This study had some limitations. First, we only had one measurement of smoking and physical activity, and our data on predictors and covariates were self-reported. Smoking history and amount of smoking were, however, asked in detail, and thus we were able to examine ex-smoking separately from non-smoking, and distinguish between moderate and heavy smoking. Since reasons for stopping smoking were not available, the results for ex-smoking should be interpreted with some caution. The measurement of leisure-time physical activity comprised four items and both quantity and intensity of activity. Although our self-reported physical activity measure lacks validation, no physical activity questionnaire has been shown to be superior to others. ${ }^{48}$ Thus, similar challenges apply to any self-reported measure, but for epidemiological research these questions are most feasible. Second, the data comprised only middle-aged public sector employees from the capital area of Finland. Municipal employees further are predominantly women whose smoking and physical activity patterns may differ from those for men. However, no 
gender interaction in the associations was found. Generalisability of these results to other employee sectors and countries could be limited, although there is no particular reason to assume why the joint effects of physical activity and smoking on disability retirement risk would largely differ between, for example, employment sectors or area of living. Although only one large employer was included, it is the largest in Finland and includes hundreds of different occupations. Third, it needs to be acknowledged that there was loss of data due to non-response to the survey (response rate 67\%) as well as not consenting to register linkages (78\% consented). Despite the potential bias or selection due to loss of participants, our thorough non-participation analyses have shown that the data are broadly representative of the target population and that non-consenting is unlikely to distort the findings. ${ }^{29} 4950$ Those who participated and consented to register linkages tended, however, to be somewhat older and had a higher socioeconomic position, as well as slightly less medically certified sickness absence.

This study also had some strengths. First, we had prospective data on disability retirement, derived from national registers. These data were complete and based on ICD-10 diagnoses. Thus, there is no loss to follow-up among those consenting to register linkage. It was also possible to distinguish other retirement types in the analyses and specifically focus on a more objective measure of disability retirement. Second, we were able to examine the joint associations of physical activity and smoking by focusing on both different levels of physical activity and amount of smoking and history. Thus, this study provides novel evidence about the importance of vigorous physical activity in efforts to prevent disability retirement among non-smokers, ex-smokers and moderate smokers. Distinguishing the amount of smoking further highlighted the importance of examining heavy smoking separately from occasional smoking, ex-smoking and non-smoking. Third, we had a set of key covariates available from the baseline survey to provide more robust evidence about the joint associations of physical activity and smoking with disability retirement.

\section{CONCLUSIONS}

Both smoking and physical inactivity are jointly associated with disability retirement, and this study showed that the risk of disability retirement due to smoking varies by the level of physical activity. Among ex-smokers and moderate smokers, vigorous physical activity might help prevent work disability, while among heavy smokers vigorous physical activity is not sufficient to eliminate the adverse effects of smoking on health and work ability. As work disability is also a major societal challenge, evidence about its preventable risk factors helps tackle the topical question of increasing labour market participation, and promotes maintenance of work ability. This not only improves health and well-being, but prevents large individual and societal costs related to work disability. Finally, interventions and efforts to promote nonsmoking are strongly recommended alongside promotion of vigorous physical activities among all employees.

Contributors All authors meet the criteria of authorship. TL, OR, EL and JL contributed to the conception of the study, and all authors planned the analysis. JL conducted all the analyses. All authors interpreted the results. TL drafted the first version of the article, and other authors critically commented and revised the text for its intellectual content. All authors also approved the submission of the final version. The guarantor, TL, affirms that the manuscript represents honest and accurate work and that all important aspects have been reported in a transparent way.

Funding The Helsinki Health Study has been supported by the Academy of Finland (\#1129225, \#1257362) and the Finnish Work Environment Fund (\#112231), University of Helsinki, the Ministry of Education and Culture (\#6303383). The funders did not participate in the planning, design or conduction of the study in any way.

\section{Competing interests None declared.}

Ethics approval The Helsinki Health Study protocol has been approved by the ethics committees of the Department of Public Health, University of Helsinki, Finland and the City of Helsinki Health Authorities.

Provenance and peer review Not commissioned; externally peer reviewed.

Data sharing statement No additional data are available.

Open Access This is an Open Access article distributed in accordance with the Creative Commons Attribution Non Commercial (CC BY-NC 4.0) license, which permits others to distribute, remix, adapt, build upon this work noncommercially, and license their derivative works on different terms, provided the original work is properly cited and the use is non-commercial. See: http:// creativecommons.org/licenses/by-nc/4.0/

\section{REFERENCES}

1. Hallal PC, Andersen LB, Bull FC, et al. Global physical activity levels: surveillance progress, pitfalls, and prospects. Lancet 2012;380:247-57.

2. Lee IM, Shiroma EJ, Lobelo F, et al. Effect of physical inactivity on major non-communicable diseases worldwide: an analysis of burden of disease and life expectancy. Lancet 2012;380:219-29.

3. Lim SS, Vos T, Flaxman AD, et al. A comparative risk assessment of burden of disease and injury attributable to 67 risk factors and risk factor clusters in 21 regions, 1990-2010: a systematic analysis for the Global Burden of Disease Study 2010. Lancet 2012;380:2224-60.

4. Ezzati M, Lopez AD. Smoking and oral tobacco use. Chapter 11. In: Ezzati M, Lopez AD, Rodgers A, et al., eds. Comparative Quantification of Health Risks Global and Regional Burden of Disease Attributable to Selected Major Risk Factors. Vol. 1. Geneva, Switzerland: The World Health Organization, 2004:883-958.

5. Finnish Centre of Pensions, The Social Insurance Institute of Finland. The Statistical Yearbook of Pensioners in Finland 2012. Helsinki: Finnish Centre for Pensions; The Social Insurance Institution of Finland, 2013.

6. Claessen $\mathrm{H}$, Arndt V, Drath $\mathrm{C}$, et al. Smoking habits and occupational disability: a cohort study of 14,483 construction workers. Occup Environ Med 2010;67:84-90.

7. Husemoen LL, Osler M, Godtfredsen NS, et al. Smoking and subsequent risk of early retirement due to permanent disability. Eur $J$ Public Health 2004;14:86-92.

8. Koskenvuo K, Broms U, Korhonen T, et al. Smoking strongly predicts disability retirement due to COPD: the Finnish Twin Cohort Study. Eur Respir J 2011;37:26-31.

9. Lund T, Csonka A. Risk factors in health, work environment, smoking status, and organizational context for work disability. AmJ Ind Med 2003;44:492-501.

10. Lincoln AE, Smith GS, Amoroso PJ, et al. The effect of cigarette smoking on musculoskeletal-related disability. Am J Ind Med 2003;43:337-49.

11. Friis K, Ekholm O, Hundrup YA. The relationship between lifestyle, working environment, socio-demographic factors and expulsion from the labour market due to disability pension among nurses. Scand J Caring Sci 2008;22:241-8. 
12. Haukenes I, Riise T, Haug K, et al. Smokers' increased risk for disability pension: social confounding or health-mediated effects? Gender-specific analyses of the Hordaland Health Study cohort. $J$ Epidemiol Community Health 2013;67:758-64.

13. Lahti J, Rahkonen O, Lahelma E, et al. Leisure-time physical activity and disability retirement: a prospective cohort study. J Phys Act Health 2013;10:669-75.

14. Williams ED, Eastwood SV, Tillin T, et al. The effects of weight and physical activity change over 20 years on later-life objective and self-reported disability. Int J Epidemiol 2014;43:856-65.

15. Gretebeck RJ, Ferraro KF, Black DR, et al. Longitudinal change in physical activity and disability in adults. Am J Health Behav 2012;36:385-94.

16. Friis K, Ekholm O, Hundrup YA, et al. Influence of health, lifestyle working conditions, and sociodemography on early retirement among nurses: the Danish Nurse Cohort Study. Scand J Public Health 2007;35:23-30.

17. van den Berg $\mathrm{T}$, Schuring $\mathrm{M}$, Avendano $\mathrm{M}$, et al. The impact of ill health on exit from paid employment in Europe among older workers. Occup Environ Med 2010;67:845-52.

18. Robroek SJ, Reeuwijk KG, Hillier FC, et al. The contribution of overweight, obesity, and lack of physical activity to exit from paid employment: a meta-analysis. Scand J Work Environ Health 2013;39:233-40.

19. Furlanetto KC, Mantoani LC, Bisca G, et al. Reduction of physical activity in daily life and its determinants in smokers without airflow obstruction. Respirology 2014;19:369-75

20. Garcia-Aymerich J, Lange $\mathrm{P}$, Benet $\mathrm{M}$, et al. Regular physical activity modifies smoking-related lung function decline and reduces risk of chronic obstructive pulmonary disease: a population-based cohort study. Am J Respir Crit Care Med 2007;175:458-63.

21. Gleeson M, Bishop NC, Stensel DJ, et al. The anti-inflammatory effects of exercise: mechanisms and implications for the prevention and treatment of disease. Nat Rev Immunol 2011;11:607-15.

22. Ropponen A, Svedberg P. Single and additive effects of health behaviours on the risk for disability pensions among Swedish twins. Eur J Public Health 2014;24:643-8.

23. Eriksen W, Natvig B, Rutle O, et al. Smoking as a predictor of long-term work disability in physically active and inactive people. Occup Med 1998;48:315-20.

24. OECD. Sickness, Disability and Work: Breaking the Barriers. A synthesis of findings across OECD countries. Paris: OECD, 2010.

25. OECD. Health at a Glance: Europe 2014, OECD Publishing. 2014.

26. OECD. Health Statistics 2014-How does Finland compare? http:// www.oecd.org/els/health-systems/Briefing-Note-FINLAND-2014.pdf (accessed 29 Mar 2015).

27. Helldán A, Helakorpi S, Virtanen S, et al. Suomalaisen aikuisväestön terveyskäyttäytyminen ja terveys, kevät 2013 (In Finnish. Health Behaviour and Health among the Finnish Adult Population, Spring 2013). Tanpere: National Institute for Health and Welfare (THL); JuvenesPrint-Suomen Yliopistopaino Oy; 2013. Report No. 21.

28. Borodulin $\mathrm{K}$, Harald $\mathrm{K}$, Jousilahti $\mathrm{P}$, et al. Time trends in physical activity from 1982 to 2012 in Finland. Scand J Med Sci Sports 2015 [Epub ahead of print 6 Jan 2015].

29. Lahelma E, Aittomäki A, Laaksonen M, et al. Cohort profile: The Helsinki Health Study. Int J Epidemiol 2013;42:722-30.

30. Rahkonen O, Laaksonen M, Karvonen S. The contribution of lone parenthood and economic difficulties to smoking. Soc Sci Med 2005;61:211-16.
31. Laaksonen $\mathrm{M}$, Rahkonen $\mathrm{O}$, Martikainen $\mathrm{P}$, et al. Smoking and SF-36 health functioning. Prev Med 2006;42:206-9.

32. Lahti J, Lallukka T, Lahelma E, et al. Leisure-time physical activity and psychotropic medication: a prospective cohort study. Prev Med 2013;57:173-7.

33. Kujala U, Kaprio J, Sarna S, et al. Relationship of leisure-time physical activity and mortality: the Finnish Twin Cohort. JAMA 1998;279:440-4.

34. Ainsworth BE, Haskell WL, Whitt MC, et al. Compendium of physical activities: an update of activity codes and MET intensities. Med Sci Sports Exerc 2000;32:S498-504.

35. Fogelholm M, Suni J, Rinne M, et al. Physical activity pie. A graphical presentation integrating recommendations for fitness and health. J Phys Activ Health 2005;2:391-6.

36. Huunan-Seppälä $\mathrm{A}$, Järvisalo $\mathrm{J}$, Laine $\mathrm{A}$, et al. The prevention of problems related to disallowed disability pensions: a report commissioned by the Parliamentary Trustees of the Social Insurance Institution, Finland. Vol. 26, 2003:1-43.

37. Martimo KP, Varonen $\mathrm{H}$, Husman $\mathrm{K}$, et al. Factors associated with self-assessed work ability. Occup Med 2007;57:380-2.

38. Haukenes I, Mykletun A, Knudsen AK, et al. Disability pension by occupational class - the impact of work-related factors: the Hordaland Health Study Cohort. BMC Public Health 2011:11:406, 2458-11-406.

39. Leinonen $\mathrm{T}$, Pietiläinen $\mathrm{O}$, Laaksonen $\mathrm{M}$, et al. Occupational socia class and disability retirement among municipal employees-the contribution of health behaviors and working conditions. Scand $J$ Work Environ Health 2011;37:464-72.

40. Lallukka T, Mauramo E, Lahelma E, et al. Economic difficulties and subsequent disability retirement. Scand J Public Health 2015:43:169-75.

41. Schofield A. The CAGE questionnaire and psychological health. $\mathrm{Br}$ Addict 1988;83:761-4.

42. Salonsalmi $\mathrm{A}$, Laaksonen $\mathrm{M}$, Lahelma $\mathrm{E}$, et al. Drinking habits and disability retirement. Addiction 2012;107:2128-36.

43. Roos E, Laaksonen M, Rahkonen O, et al. Relative weight and disability retirement: a prospective cohort study. Scand J Work Environ Health 2013;39:259-67.

44. Ware JE, Snow KK, Kosinski M, et al. SF-36 Health Survey: manual and interpretation guide. Boston, MA: The Health Institute, New England Medical Center, 1993.

45. Ware JE, Kosinski M, Keller SD. SF-36 physical and mental component summary measures: a user's manual. Boston, MA: The Health Institute, New England Medical Center, 1994.

46. Pietiläinen $\mathrm{O}$, Laaksonen $\mathrm{M}$, Rahkonen $\mathrm{O}$, et al. Self-rated health as a predictor of disability retirement-the contribution of ill-health and working conditions. PLOS ONE 2011;6:e25004.

47. Paavola M, Vartiainen E, Haukkala A. Smoking from adolescence to adulthood: the effects of parental and own socioeconomic status. Eur J Public Health 2004:14:417-21.

48. van Poppel MN, Chinapaw MJ, Mokkink LB, et al. Physical activity questionnaires for adults: a systematic review of measurement properties. Sports Med 2010;40:565-600.

49. Laaksonen M, Aittomäki A, Lallukka T, et al. Register-based study among employees showed small nonparticipation bias in health surveys and check-ups. J Clin Epidemiol 2008:61:900-6.

50. Martikainen $\mathrm{P}$, Laaksonen M, Piha K, et al. Does survey non-response bias the association between occupational socia class and health? Scand J Public Health 2007;35:212-15. 